\title{
Influence of large-scale structures on the stability of the hangingwall in a caving mine: a modelling study
}

\section{Sraj Banda Umar* and Catrin Edelbro}

Division of Mining and Geotechnical Engineering,

Department of Civil, Environmental

and Natural Resources Engineering,

Luleå University of Technology,

Luleå, SE-97187, Sweden

Email: sraj.banda@1tu.se

Email: Catrin.Edelbro@1tu.se

${ }^{*}$ Corresponding author

\begin{abstract}
The Printzsköld orebody in the Malmberget mine of Northern Sweden is currently under production and is centrally located in the mining area. The effects of the on-going sublevel cave-mining in this orebody are currently investigated with respect to cave development with an initial emphasis on the effects of stress redistribution and potential rock mass yielding. In this study, three-dimensional discontinuum modelling of the Printzsköld orebody is presented, in which the effect of three pre-existing large-scale geological structures have been studied. The results of the present study showed low stress build-ups in the crown pillar and cave bottom, due to shear slip developing along the structures. The presence of large-scale structures has no significant effects on the far-field stresses as shear slip along these structures is confined to cave boundaries. An analysis of the shear strength of the structures showed larger effects of slip on reducing friction angle than the reduction of cohesion.
\end{abstract}

Keywords: large-scale structures; shear slip; hangingwall stability; Printzsköld orebody; failure mechanism; numerical analysis.

Reference to this paper should be made as follows: Umar, S.B. and Edelbro, C. (2016) 'Influence of large-scale structures on the stability of the hangingwall in a caving mine: a modelling study', Int. J. Mining and Mineral Engineering, Vol. 7, No. 4, pp.294-312.

Biographical notes: Sraj Banda Umar did his undergraduate and Master's Education at the University of Zambia, where he received both Bachelor and Master's degrees in Minerals sciences. Currently, he is a $\mathrm{PhD}$ candidate at the Luleå University if Technology in Sweden.

Catrin Edelbro holds a Doctorate in Rock Mechanics and is currently senior in the Department of Civil, Environmental and Natural Resources Engineering. 


\section{Introduction}

\subsection{Caving due to mining}

Caving of the rock mass is a necessary component in cave mining. In sublevel caving, the mining method is based on the principle of gravity flow of the blasted ore rock (Brunton et al., 2010). To understand the processes that take place during caving, Duplancic and Brady (1999) suggested a conceptual model for the caving zone, in which various regions of the zone were categorised with respect to their seismic and discontinuity responses, see Figure 1.

Figure 1 The conceptual model describing generally a mine induced caving zone as proposed by Sainsbury (2012), based on Duplancic and Brady (1999) (see online version for colours)

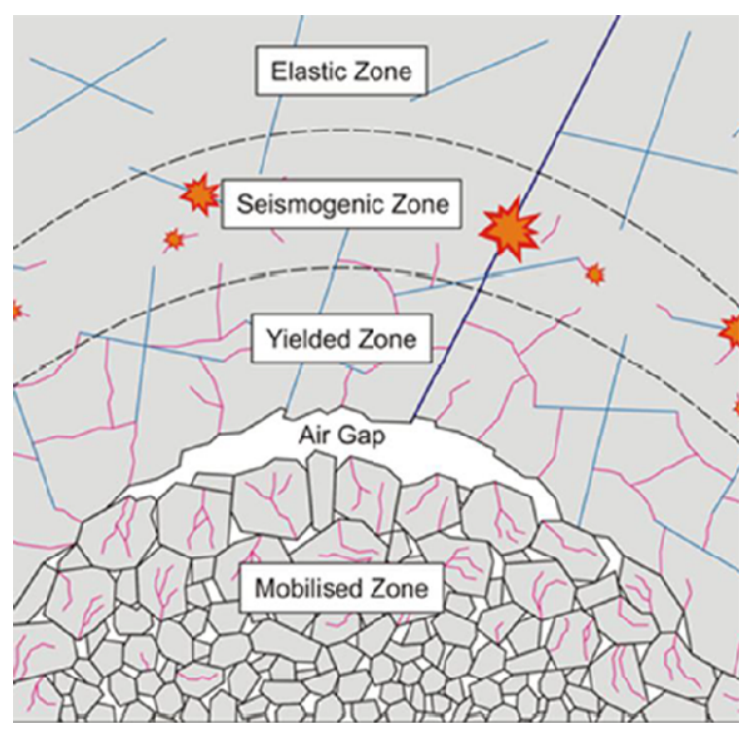

The descriptions of the different zones in Figure 1 are (Duplancic and Brady, 1999; Sainsbury, 2012; Sainsbury et al., 2011a):

\section{- Elastic zone}

In this zone, the rock mass surrounds the caving zone and behaves mostly elastically, with properties consistent with an undisturbed rock mass.

\section{- $\quad$ Seismogenic zone}

In this region, there is a concentration of seismic activities. The active seismic front that occurs here results from slip on geologic structures and failure of intact rock. This is caused by the redistribution of stresses during mining and cave advance.

\section{- $\quad$ The yielded zone}

This is a zone in which rock has failed and cannot provide support to the overlying rock mass. Stresses in this region have exceeded peak strength and the rock mass is at or near 
residual strength. It is characterised by large-scale displacements of rock masses, which is subjected to significant damage (Sainsbury, 2012).

\section{- $\quad$ The air gap}

This is space left between the mobilised zone and yielded zone. The air gap is controlled by rate of draw from below and the bulking porosity of the broken material. If the rate of draw is very low the material may fill the cave and further yielding and cave advance upwards may be stopped. Furthermore, at this point the material in the cave may provide support to the walls of the cave (Villegas et al., 2011).

\section{- $\quad$ The mobilised zone}

This zone is characterised by dislodged or fallen rock blocks from the cave back. The rock usually has displacements of more than 1-2 m (Sainsbury et al., 2011a).

The ground surface above the caving zone often suffers large-scale deformations. These deformations can be evidenced by cracking, stepping, sinkhole formation, etc. Categorisation of these zones was done by, e.g., Herdocia (1991) and Lupo (1998). In sublevel caving, the deformation zones differ as suggested by Lupo (1997) in relation to the effects on the hangingwall. In this paper, the following descriptions of the deformation zones have been adopted (Lupo, 1998):

- In the caved zone a downward movement of caved material is present.

The caved material comes from collapse of material from the side walls and back of the cave.

- The fractured zone is characterised by tension cracks, steps, fractures and sinkholes or pits distributed randomly in the caving zone. In this zone, it is expected to find unstable parts as failure through toppling and shear can occur.

- The continuous deformation zone is characterised by the development of continuous distortions of the rock mass bounding the fractured zone. The variation in ground level and coordinates of positions can be detected through surveying activities.

\subsection{Influence of large-scale structures on caving}

Large-scale structures are believed to influence the cap rock stability as well as the direction of caving and the propagation and shape of the cave formed. Vyazmensky et al. (2010) found that the direction of the cave propagation is highly influenced by the orientation of large-scale structures, such as faults. Following from the conceptual model of caving by Duplancic and Brady (1999), Sainsbury et al. (2011b) used the computer code $F L A C^{3 D}$ to determine the influence of large-scale structures and it was found that the crater formed during caving and its progression followed the orientation of faults, if present in the cave area.

This result is important in relating cave advance with respect to the orientation of large-scale structures. The influence of geologic structures has also been discussed in Sainsbury et al. (2008, 2009), Sainsbury (2010) and Lupo (1997). It was evident from these studies that there exists a link between large-scale structure orientations and cave advance in a caving zone. 


\subsection{Influence of mining depth}

It is expected empirically that as mining proceeds to lower depths the effects associated with caving angles and extents of the caved zones on surface decreases. However, Woo et al. (2013), in their study of a comprehensive database of cave mining operations and caving-induced ground deformations, concluded that it is not enough to use empirical data to predict the characteristics and geometry of the caved zone. By using numerical analysis it was shown that in fact the caved zone extents increase with respect to small displacements and that subsidence angles increase with increasing mining depth. The caution has been not to rely on empirical design chart for estimating the extents of caving-induced subsidence.

\subsection{Problem statement}

The Printzsköld orebody is part of the LKAB Malmberget underground mine, and mined using sublevel caving. A particular aspect of this non-daylighting orebody is to assess the caving patterns in the cap rock overlying the orebody. Previous work has included continuum conceptual modelling in which two conceptual models have previously been analysed for this orebody to determine the stress patterns in the hangingwall as mining deepens. The first included a conceptual two-dimensional analysis in which strength parameter sensitivities were evaluated (Umar et al., 2013). The second model was a three-dimensional model, in which further studies of stress distribution and rock mass yielding was conducted. These two models were run using continuum approaches. However, the Printzsköld orebody host rock is a highly jointed rock mass and the potential effects of inferred large-scale structures in the rock mass around Printzsköld has not been quantified. In this paper, a discontinuum modelling approach, with large-scale structures explicitly included, was used to simulate the behaviour of the rock mass during loading and unloading as mining proceeds to lower levels in this orebody.

\subsection{Objectives and scope of this paper}

The objective of this paper is to conceptualise and analyse the effects of varying strength properties of the large-scale structures on the failure mechanism and the cap rock stability of the Printzsköld orebody. Hence, this study seeks to investigate the characteristics and type of yielding in the crown pillar and the hangingwall. The paper focusses on the large-scale structures that have been inferred for the Printzsköld orebody (Magnor and Mattsson, 2010). Small-scale structures have not been considered because of the model size and that those structures are not persistent enough in comparison to the model scale.

\section{The Printzsköld orebody}

The Printzsköld orebody is one of $\sim 20$ orebodies making up the Malmberget mine in Sweden, out of which about 10 are currently in production. The mining method in this orebody is sublevel caving with the current mining activities taking place at the $970 \mathrm{~m}$ level. The orebody is located almost in the middle of the mining area, does not daylight 
and strikes at $\sim 40^{\circ}$ from the magnetic north with a dip of $\sim 60^{\circ}$ towards the south (Wettainen, 2010). The average thickness of the non-daylighting orebody is $50 \mathrm{~m}$ and its top is situated $\sim 600 \mathrm{~m}$ below the ground surface $(780 \mathrm{~m}$ level in the mine coordinate system). The average strike length for the upper part of the orebody is around $400 \mathrm{~m}$ while for the lower part the orebody is more than $900 \mathrm{~m}$ in length along strike.

The deposit is a paleoproterozoic succession of greenstones, porphyries and clastic meta-sediments which are hosted by metavolcanics that have been intruded by pegmatites and granites. The volcanic rocks have been transformed to sillimanite gneisses with quartz, muscovite and local andalusite by the young granite intrusions. The iron ores are characterised by coarse magnetite and variable horizons of apatite with local sections rich in hematite. Generally, the border zones of the ore are characterised by skarn zones interpreted to be related to the formation of the ore (Romer, 1996). Similar to many areas in Northern Sweden, the Malmberget deposit is characterised by NW-SE trending shear zones (Romer, 1996). These zones are thought of as resulting from a complex geodynamic evolution which included repeated extensional and compressional tectonic regimes associated with magmatic and metamorphic events (Skiöld, 1988). The rock mass of the Printzsköld orebody has also been described in, e.g., Martinsson and Hansson (2004) and Banda (2013).

Magnor and Mattsson (2010) identified a number of potential large-scale structures in the Malmberget area. Table 1 shows descriptions of the large-scale structures inferred to in the vicinity of the Printzsköld orebody, adapted from Magnor and Mattsson (2010), as reported in Wettainen (2010).

Table 1 Classification of the large-scale structures influencing rock mass stability in the Printzsköld orebody

\begin{tabular}{llcl}
\hline $\begin{array}{l}\text { Structure } \\
\text { ID }\end{array}$ & Classification & $\begin{array}{c}\text { Dip/DD* } \\
{\left[{ }^{\circ}\right]}\end{array}$ & Description \\
\hline DZ050 & Brittle structure & $70 / 315$ & $\begin{array}{l}\text { Indicated by magnetic and gravimetric measurements and } \\
\text { core drillholes. Length estimated to } 400 \mathrm{~m} \text { and width to } \\
5 \mathrm{~m}\end{array}$ \\
DZ031 & $\begin{array}{l}\text { Probably brittle } \\
\text { structure }\end{array}$ & $80 / 003$ & $\begin{array}{l}\text { Indicated by magnetic measurements, resistivity } \\
\text { measurements and seismic reflection. Length estimated to } \\
900 \mathrm{~m} \text { and width to } 15 \mathrm{~m}\end{array}$ \\
DZ032 & $\begin{array}{l}\text { Brittle structure } \\
\text { (high fracture } \\
\text { frequency) }\end{array}$ & $68 / 167$ & $\begin{array}{l}\text { Indicated by field observations above ground and by } \\
\text { resistivity measurements. Length estimated to } 500 \mathrm{~m} \text { and } \\
\text { width to } 5 \mathrm{~m}\end{array}$ \\
\hline
\end{tabular}

*DD = dip direction.

Source: Adapted from Wettainen (2010).

An illustration of the large-scale structures in relation to the $920 \mathrm{~m}$ mining level in the Printzsköld orebody is shown in Figure 2. These large-scale structures are expected to affect the hangingwall and the cave that develops as mining progresses toward depth. It is assumed and inferred from literature that these large-scale structures are persistent throughout the mining levels and as such they are portrayed to transcend all level boundaries. 
Figure 2 Illustration and setting of three large-scale structures in the Printzsköld orebody in relation to the $920 \mathrm{~m}$ mining level (Wettainen, 2010) shown in (a) a plan view and (b) a longitudinal cross-section (see online version for colours)

a)

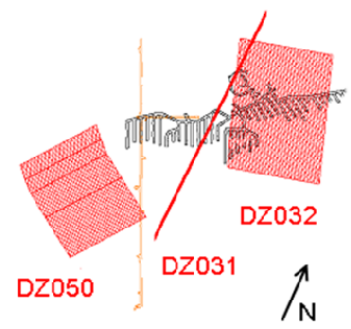

b)

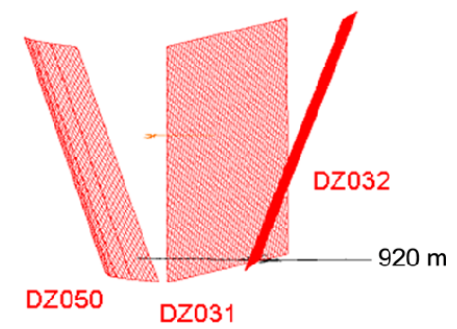

\section{Numerical modelling}

\subsection{Modelling approach, set-up and input data}

In this study, the three-dimensional discrete element code (3DEC) (Itasca Consulting Group Inc., 2013) was used as the modelling software. The choice of this modelling tool was due the ability of $3 D E C$ to model many discontinuities and the behaviour of these discontinuities; the rotation, separation and slip between blocks, as well as deformation and yielding within the rock blocks, which is useful for continued future studies. However, as a start, and for this study, only three discontinuities have been included for this conceptual investigation in this study.

The model is shown in Figure 3, with the large-scale structures indicated. A MohrCoulomb elastic-perfectly plastic material model was used which was constructed to mine-scale size, covering 3600 by 2800 by $2050 \mathrm{~m}$. The elastic constants and the strength parameters for the block material (between the structures) were taken from Sjöberg and Jacobsson (2007) and are presented in Table 2. Umar et al. (2013) also presented additional rock mass properties such as the geological strength index (GSI), uniaxial compressive strength (UCS) and calculated $\sigma_{\mathrm{cm}}$ (rock mass strength) which, together with the results from the rock mass properties study by Sjöberg and Jacobsson (2007), formed the basis of the model input parameters. As this was still at a conceptual level, the model was not validated against other field observation or monitoring data.

Several assumptions were made with regard to the modelling of the Printzsköld orebody. Firstly, it was assumed that the mining taking place in the nearby orebodies did not have an effect on the stress redistribution in the Printzsköld orebody. The current cave was simulated as a void, which has progressed to $\sim 300 \mathrm{~m}$ below the ground surface. This approach could be used since leaving a void in the model, when compared with filling it with caved rock, would not significantly affect the stress redistribution in the cap rock of the Printzsköld orebody. Lastly, cave mining was simulated by removing one sublevel at a time, and as mining progressed a void was left in the minedout areas. Caving of the overlying rock mass was not explicitly simulated in this conceptual model.

In this study, the laboratory-scale properties of the structures have been used due to lack of representative large-scale structure strength properties. Due to scale dependency it is likely that the large-scale structures have lower strength properties compared with 
laboratory-scale. A Coulomb slip model was assumed for the joints. Three simulations were conducted, the first of which was the base case. Cohesion and internal friction angle were varied as shown in Table 3 for the remaining two model simulations. This was used to determine their effect on the stability of the hangingwall and the crown pillar as mining proceeded to lower levels.

Figure 3 Model set-up showing large scale structure positions in the Printzsköld orebody (see online version for colours)

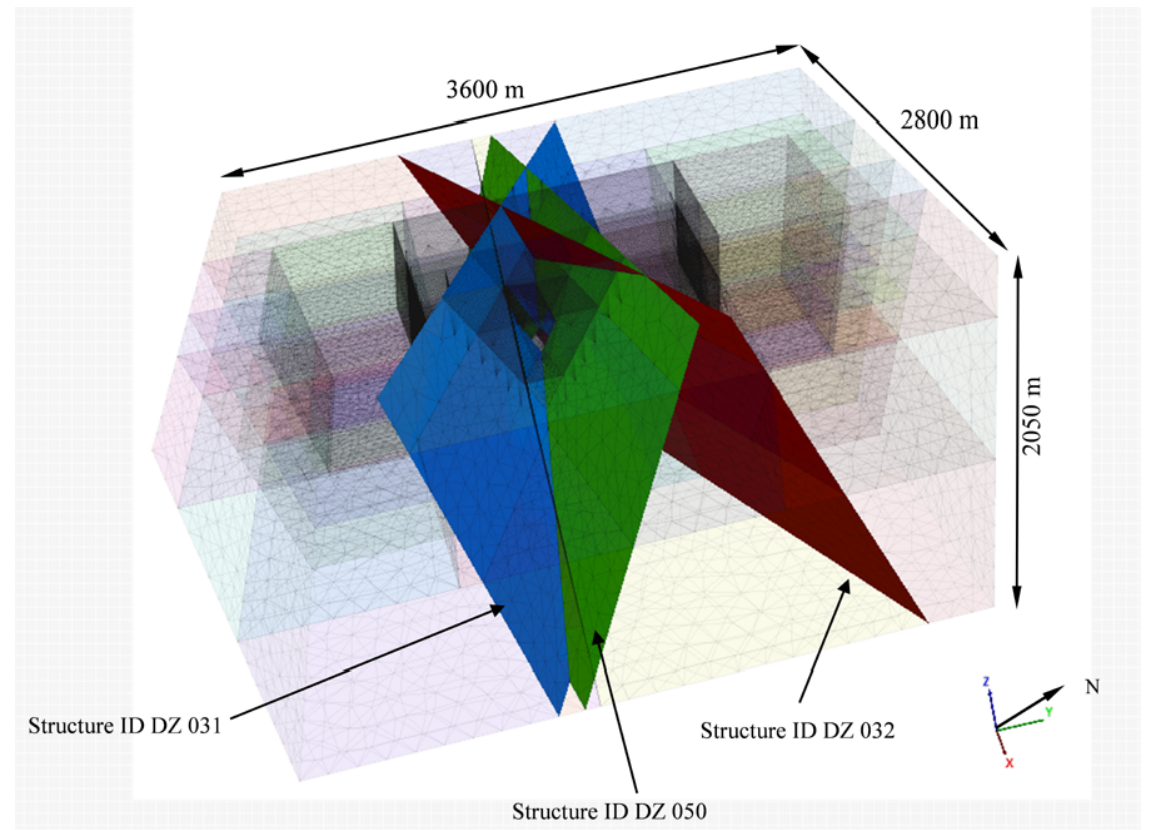

Table 2 Input parameters used for the elastic-perfectly plastic model

\begin{tabular}{lcc}
\hline Area & Strength parameter & Value \\
\hline Hangingwall & $c_{m}[\mathrm{MPa}]$ & 5.18 \\
& $\varphi_{m}\left[{ }^{\circ}\right]$ & 50.7 \\
Orebody & $\sigma_{t m}[\mathrm{MPa}]$ & 0.71 \\
& $c_{m}[\mathrm{MPa}]$ & 4.81 \\
& $\varphi_{m}\left[{ }^{\circ}\right]$ & 50.7 \\
Footwall & $\sigma_{t m}[\mathrm{MPa}]$ & 0.48 \\
& $c_{m}[\mathrm{MPa}]$ & 6.67 \\
& $\varphi_{m}\left[{ }^{\circ}\right]$ & 52.9 \\
\hline
\end{tabular}

$c_{m}=$ cohesion of rock mass; $\varphi_{m}=$ rock mass internal friction angle; $\sigma_{t m}=$ rock mass tensile strength.

Source: Sjöberg and Jacobsson (2007) 
Table 3 Strength parameters for the large scale structures in the Printzsköld orebody obtained (from laboratory shear tests of the Printzsköld orebody joints)

\begin{tabular}{lccccc}
\hline Case & $c_{j}(\mathrm{MPa})$ & $\varphi_{j}\left({ }^{\circ}\right)$ & $\sigma_{t j}(\mathrm{MPa})$ & $k_{s}(\mathrm{GPa})$ & $k_{n}(\mathrm{GPa})$ \\
\hline Base case & 0.64 & 37 & 0 & 10.3 & 28.1 \\
Low cohesion & 0 & 37 & 0 & 10.3 & 28.1 \\
Low friction & 0.64 & 27 & 0 & 10.3 & 28.1 \\
angle & & & & & \\
\hline
\end{tabular}

$c_{j}=$ joint cohesion; $\varphi_{j}=$ friction angle of joint; $\sigma_{t j}=$ joint tensile strength; $k_{s}=$ shear

stiffness; $k_{n}=$ normal stiffness.

Initial stresses used were taken from a study by Sjöberg (2008) in which the vertical stresses were set equal to the pressure from overlying rock material and the horizontal stresses were found to be (through stress calibration against conducted stress measurements):

$$
\begin{gathered}
\sigma_{H}=0.0358 \cdot z \\
\sigma_{h}=0.0172 \cdot z .
\end{gathered}
$$

Here, $z$ is the vertical depth in metres and all stresses are in MPa with $\sigma_{\mathrm{H}}$ being the maximum horizontal stress and $\sigma_{\mathrm{h}}$ the minimum horizontal stress and with $\sigma_{\mathrm{H}}$ having an orientation of $130.6^{\circ}$ from the local north of the mine. The horizontal-to-vertical stress ratio(for the maximum horizontal stress) is thus $K_{0}=1.33$. The boundary conditions used were zero-velocity ('roller') boundaries on the vertical boundaries of the model, as well as for the bottom boundary. The ground surface was modelled as a free surface.

\subsection{Evaluation approach}

Six evaluation planes (C1, C2, C3 and L1, L2, L3) were used in this study, see Figures 4 and 5. The locations of the ' $C$ ' and ' $L$ ' evaluation planes were chosen based on the need for comparisons of stress redistributions in both the hangingwall and cap rock. Yielding was studied on two evaluation planes - $\mathrm{C} 1$ (situated about $50 \mathrm{~m}$ from the cave back) and L1 (cutting through the cave back). Both stress distribution and rock mass yielding was studied. Additionally, the developed slip along the large-scale structures was analysed and the potential effects on the stability of the hangingwall and crown pillar of the orebody assessed. The evaluation of the result in this study enabled a better comparison of results and to see the effects of changing the model from continuum to discontinuum and the inclusion of large-scale structures in the model. These comparisons were made on the orebody axis, and the $\mathrm{C} 1$ and L1 evaluation planes. This comparison served to find the different model responses with varying conceptualisations of the model in an effort to best represent the rock mass.

\section{Model results}

\subsection{Stress analysis}

Three discontinuum cases were simulated and as an example the stress redistribution results for evaluation plane L1 after mining the $1225 \mathrm{~m}$ level are presented in Table 4. 
Also presented in Table 4 are continuum modelling stress results from a previous study by Umar et al. (2015), undertaken for the same orebody. The evaluation plane L1 represents the vertical cross-section along the Printzsköld orebody at which maximum stress redistribution in the cap rock and hangingwall would be more evident compared with the L2 and L3 planes. There were no significant differences observed among the three discontinuum cases. However, a difference was observed when the discontinuum cases were compared with the continuum model results. A lower stress build-up was observed in the discontinuum model compared with the continuum models.

Figure 4 Evaluation planes C1, C2 and C3 in the vertical cross-sectional view of the Printzsköld orebody. Horizontal colour differences represent various mining levels in the orebody (see online version for colours)

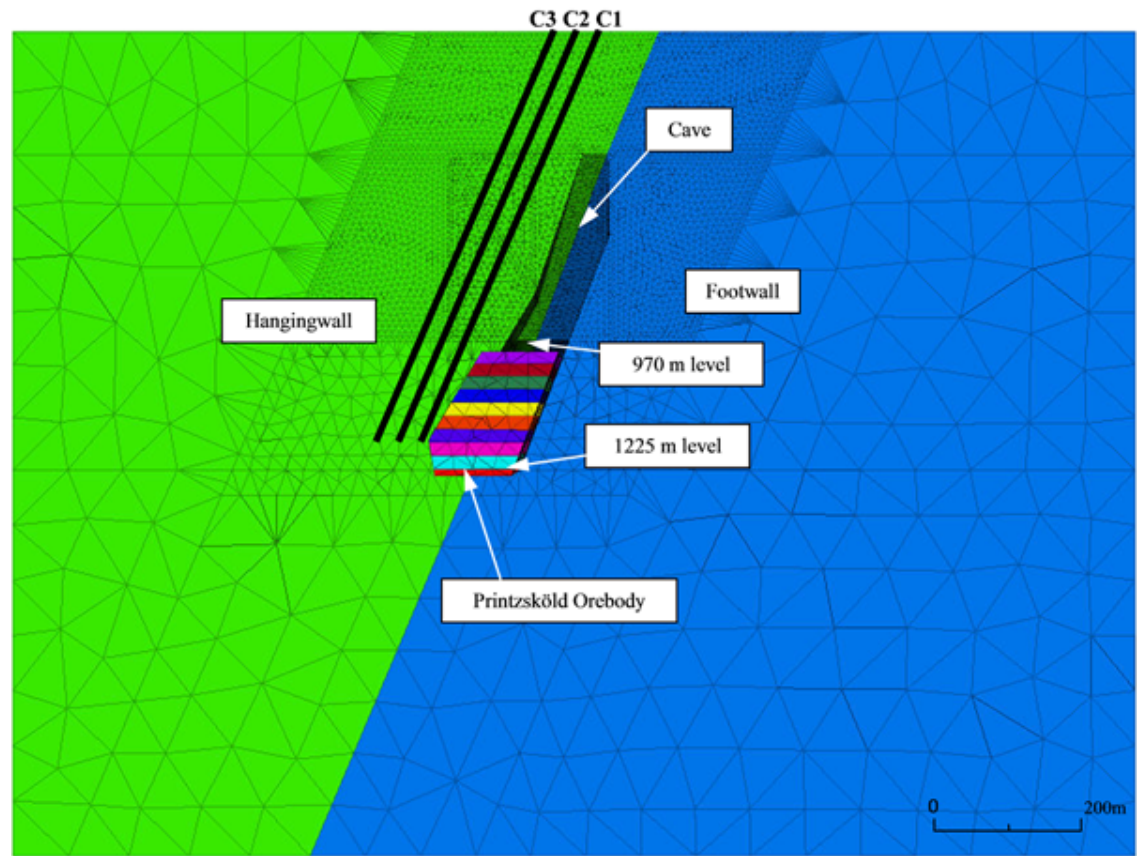

The maximum stresses in the crown pillar and cave bottom area were calculated in each of the models and compared. They were evaluated on the L1 evaluation plane. The two areas were selected for stress observation because they were the most sensitive sections to stress changes in the simplified geometry of the Printzsköld orebody. Stress comparisons for the two areas are presented in Table 5 for the continuum and discontinuum models. The continuum model resulted in higher stresses in the cap rock and the cave bottom compared with the discontinuum model. The difference in stress build-up is attributed to the inclusion of the structures in the discontinuum model. Comparisons of the distressed regions in the hangingwall did not show significant differences in terms of area of distressing for the continuum vs. the discontinuum models. 
Table 4 Results for the continuum and discontinuum models in terms of maximum principal stress on the evaluation plane L1, for the Printzsköld orebody after mining the $1225 \mathrm{~m}$ level (see online version for colours)

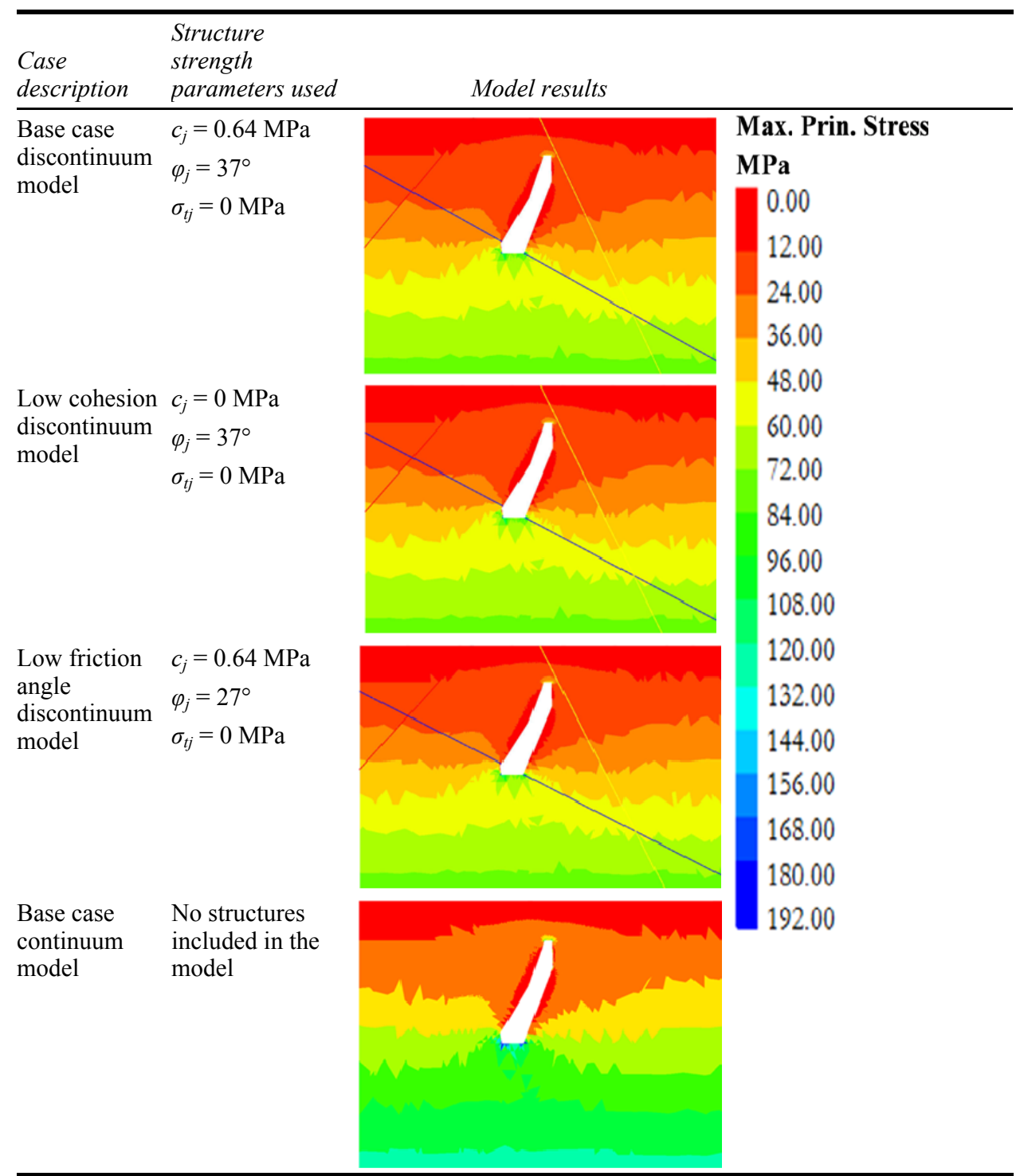

$c_{j}=$ Joint cohesion $[\mathrm{MPa}] ; \varphi_{j}=$ Joint friction angle $\left[{ }^{\circ}\right] ; \sigma_{t j}=$ Tensile strength of the joint $[\mathrm{MPa}]$.

Table 5 Major principal stresses calculated from the $3 D E C$ model in the cap rock roof and cave bottom for the continuum and discontinuum models

\begin{tabular}{lcc}
\hline Orebody area under comparison & Continuum model $[\mathrm{MPa}]$ & Discontinuum model $[\mathrm{MPa}]$ \\
\hline Crown pillar & 72 & 48 \\
Cave bottom & 192 & 144 \\
\hline
\end{tabular}


An additional evaluation of stress redistribution was conducted on a plane passing through the orebody axis along the longitudinal section parallel to the orebody strike. A comparison of stress levels in the plunge hangingwall was also conducted. The results are presented in Figure 6 (a) and (b). There is a slightly reduced build-up of stresses in the plunge hangingwall in the discontinuum model (Figure 6(a)) when compared with that seen in the continuum model (Figure 6(b)).

Figure 5 Evaluation planes L1, L2 and L3 in the longitudinal view of the Printzsköld orebody. Horizontal colour differences represent various mining levels in the orebody (see online version for colours)

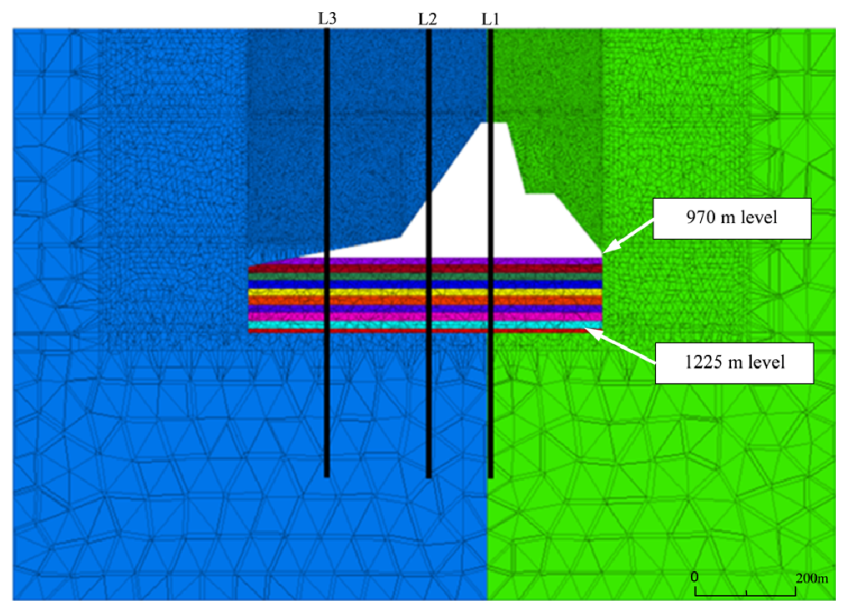

Figure 6 Maximum principal stress on the longitudinal section along the centre plane of the orebody for: (a) the discontinuum model and (b) the continuum model, after mining to the $1225 \mathrm{~m}$ level (see online version for colours)

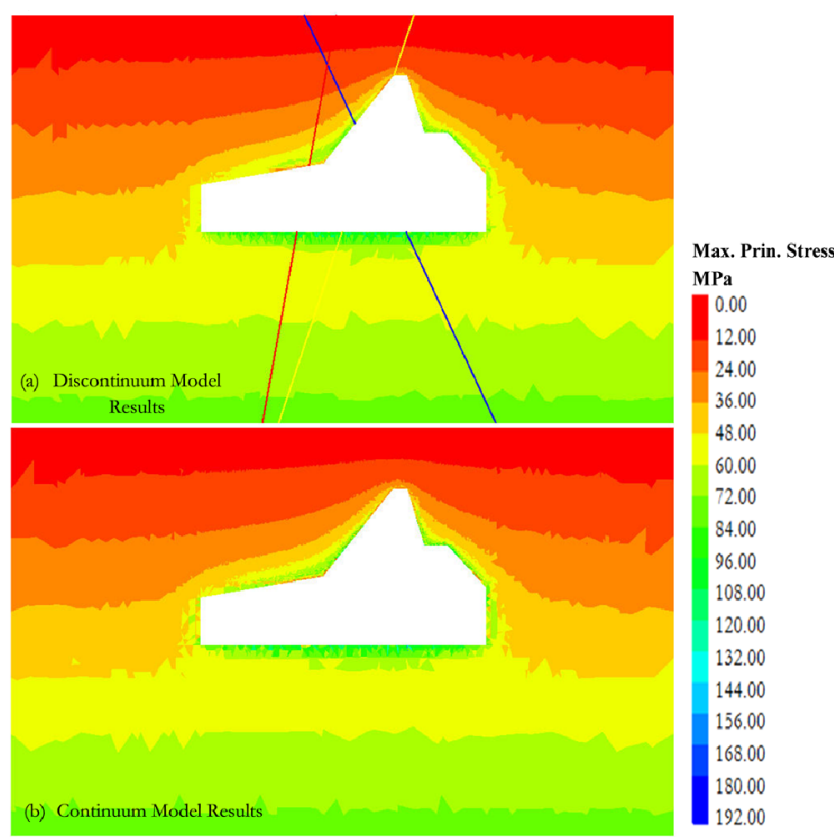




\subsection{Joint slip and rock mass yielding}

It was observed that there was slip on all the large-scale structures especially around the cave boundaries for all simulated mining stages. The calculated slip for the three different strength cases is presented in Table 6. It was found that decreasing the strength parameters for the large-scale structures had an effect of increased slip area along two of the structures, DZ031 and DZ050. This is believed to be linked to the setting of the structures. These two structures have in common the near parallel strike to that of the maximum horizontal stress direction compared with DZ032. Furthermore, DZ032 has a shallower dip compared with DZ031 and DZ050.

Table 6 Numerical modelling results showing the calculated slip (in reddish-brown) on the three structures with the various strength parameters after mining the $1225 \mathrm{~m}$ level.

Viewed from the south and parallel to the strike of the Printzsköld orebody (see online version for colours)

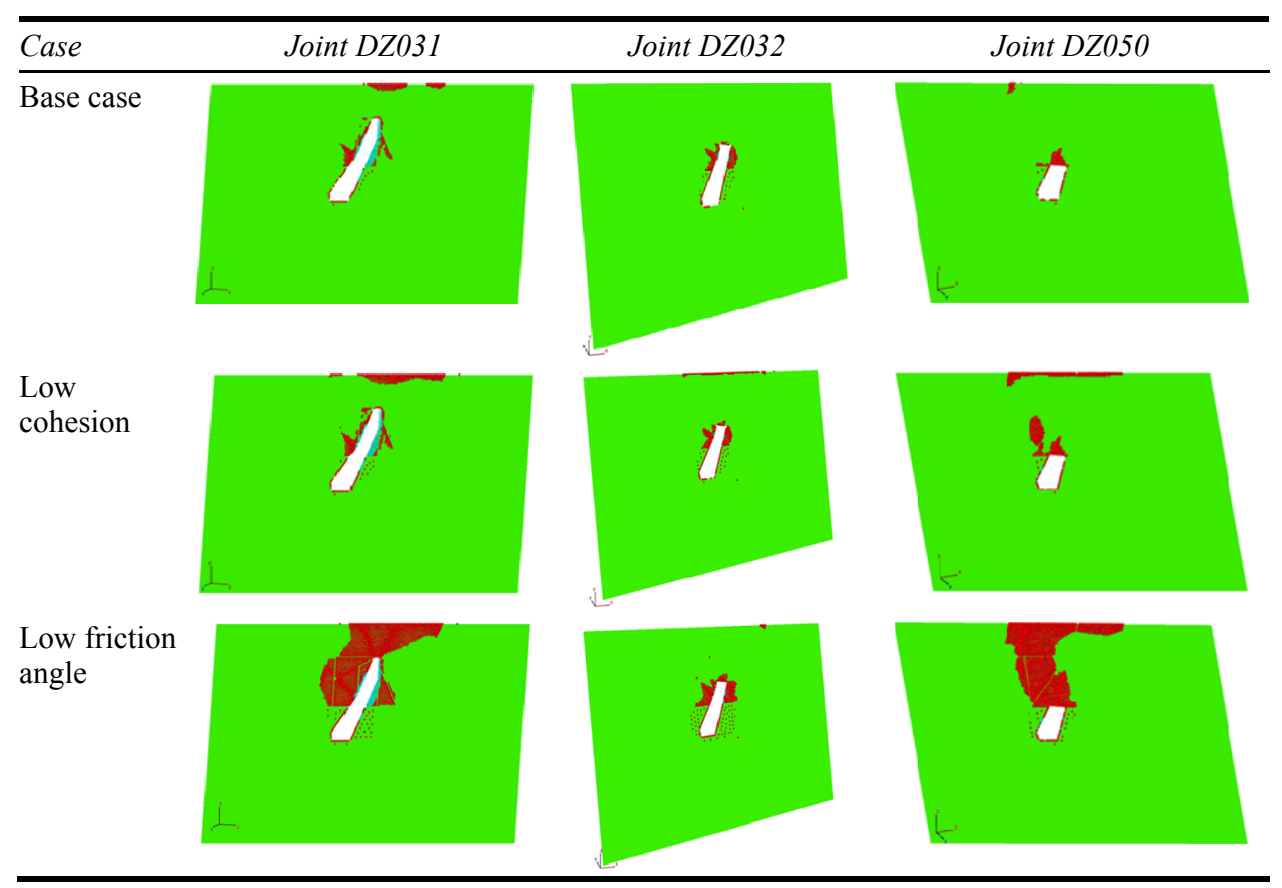

Changing the large-scale structure friction angle was much more sensitive than changing the cohesion with respect to area of slip on the structures, as can be seen in Figure 7. Thus, it appears that the normal stress is a major contributing factor, along with the orientations of the large-scale structures.

Except in the cases where the strength parameters were decreased, slip was observed to be confined mainly to the mine openings (cave). There was also tensile failure observed along all the structures in both the hangingwall and footwall, see Figure 8. 
Figure 7 Calculated slip areas on the modelled large-scale structures for the three different strength cases simulated in the model of the Printzsköld orebody and for mining to the $1225 \mathrm{~m}$ level (see online version for colours)

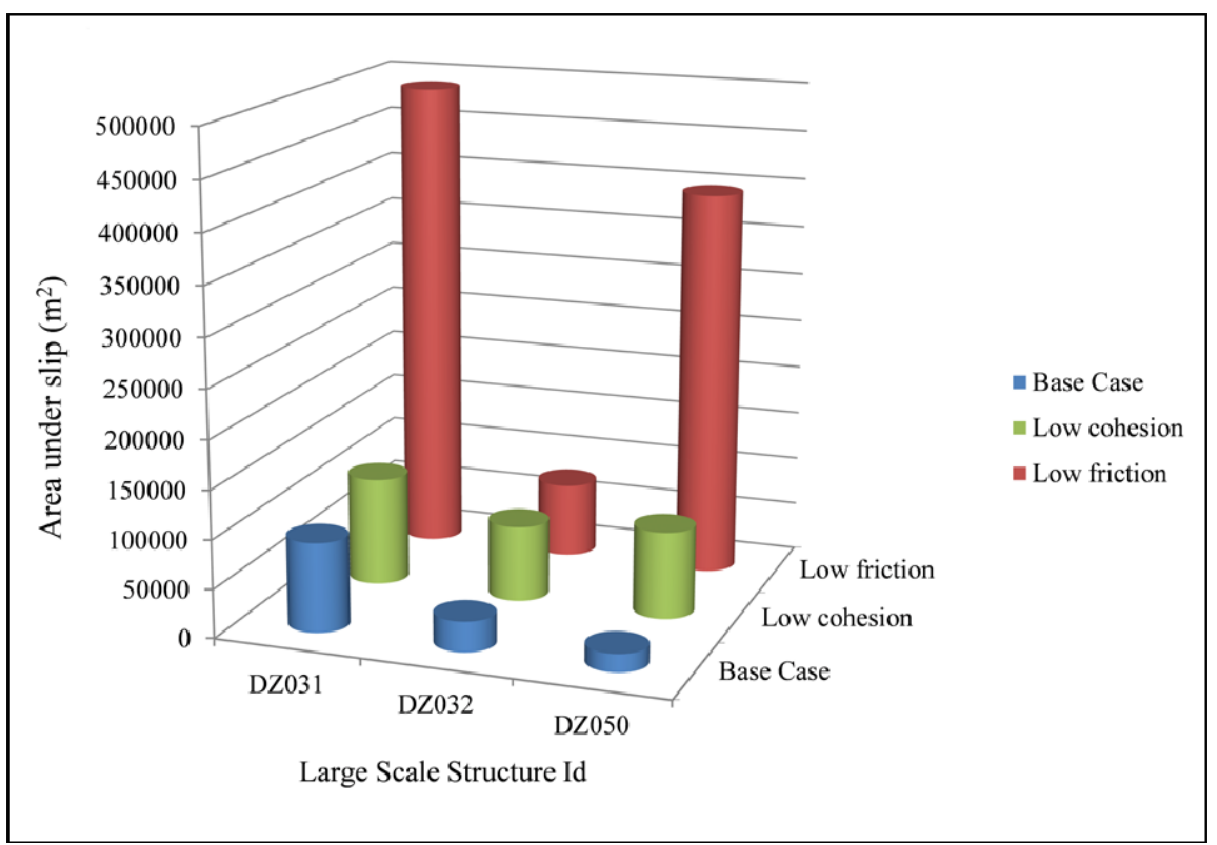

Figure 8 Calculated slip along the large-scale structures after mining down to $1225 \mathrm{~m}$. Red spots indicate past slip along the structures (see online version for colours)

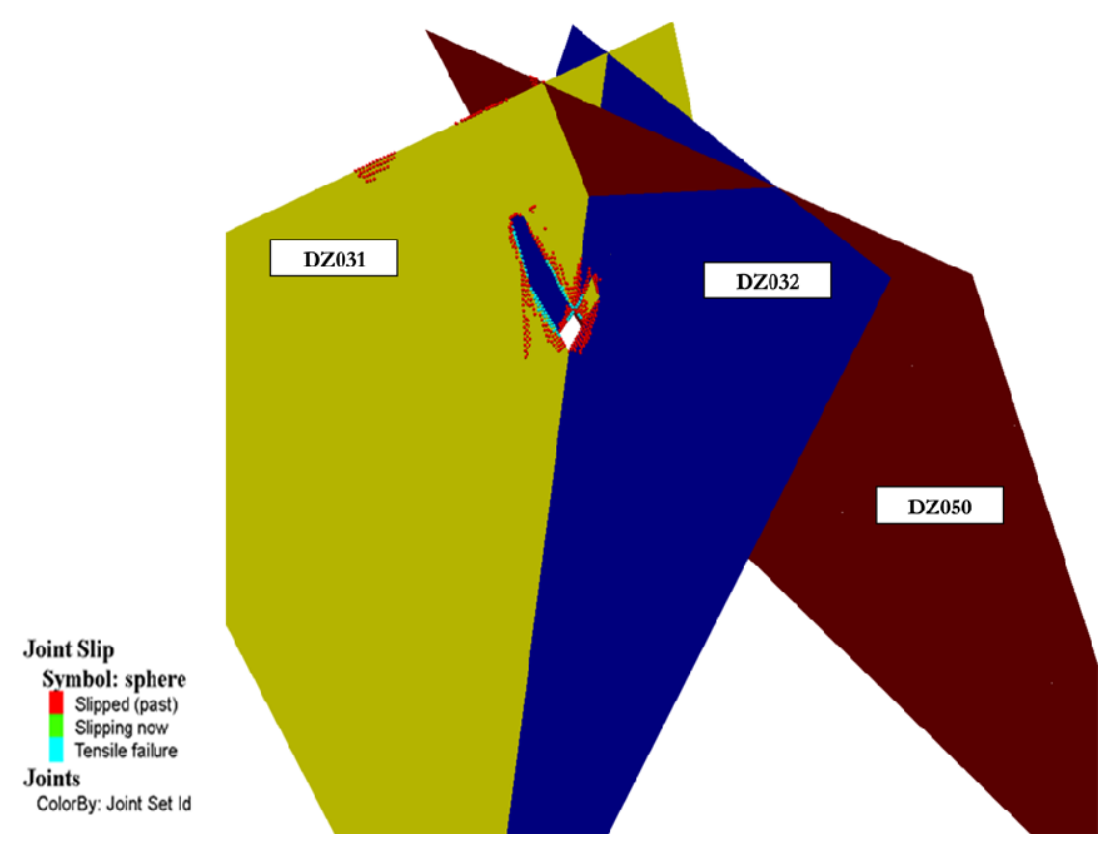


Figure 9 Calculated yielding in the Printzsköld orebody evaluated on the L1 evaluation plane using $3 D E C$ from the continuum model in a previous study yet to be published in (a) and from the current discontinuum model in (b), after mining to the $1225 \mathrm{~m}$ level (see online version for colours)
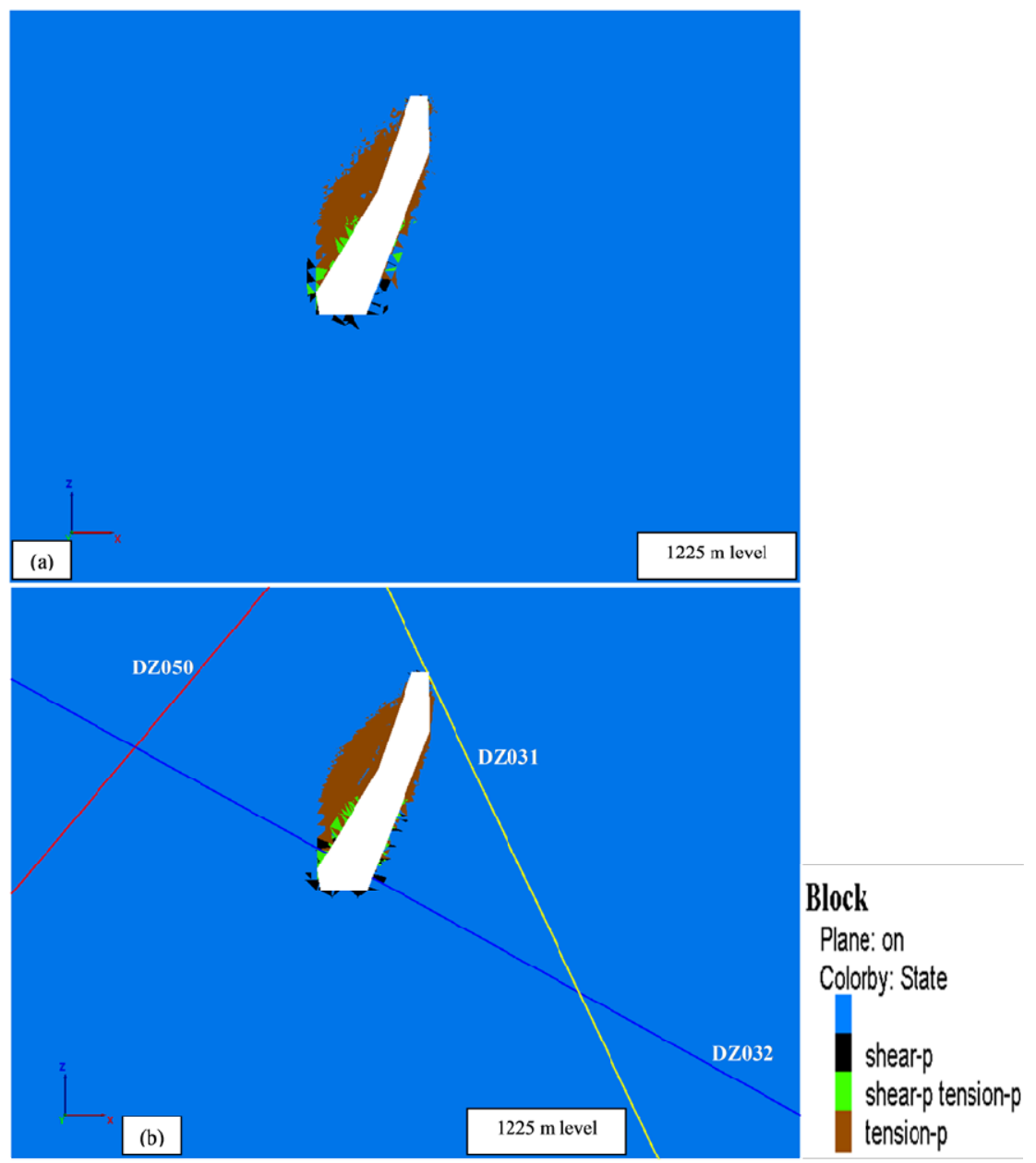

Yielding in the rock mass was evaluated using the $\mathrm{C} 1$ and L1 evaluation planes, see Figures 9 and 10. Comparisons of the yielding pattern in the rock mass were made between the continuum and the discontinuum models. This comparison showed that there were no significant differences between the continuum and discontinuum yielding results for both the vertical and the longitudinal evaluation sections. The legend shows yielding in shear and tension. 'Shear-p' indicates shear yielding in the past (i.e., in previous calculations time steps), 'tension-p' indicates tension in the past, 'shear-p tension-p' denotes a mixture of the two yielding mechanisms, and the blue colour shows material still in elastic state. 
Figure 10 Calculated yielding in the Printzsköld orebody evaluated on the $\mathrm{C} 1$ evaluation plane using $3 D E C$ from the continuum model in a previous study in (a) and from the current discontinuum model in (b), after mining to the $1225 \mathrm{~m}$ level (see online version for colours)

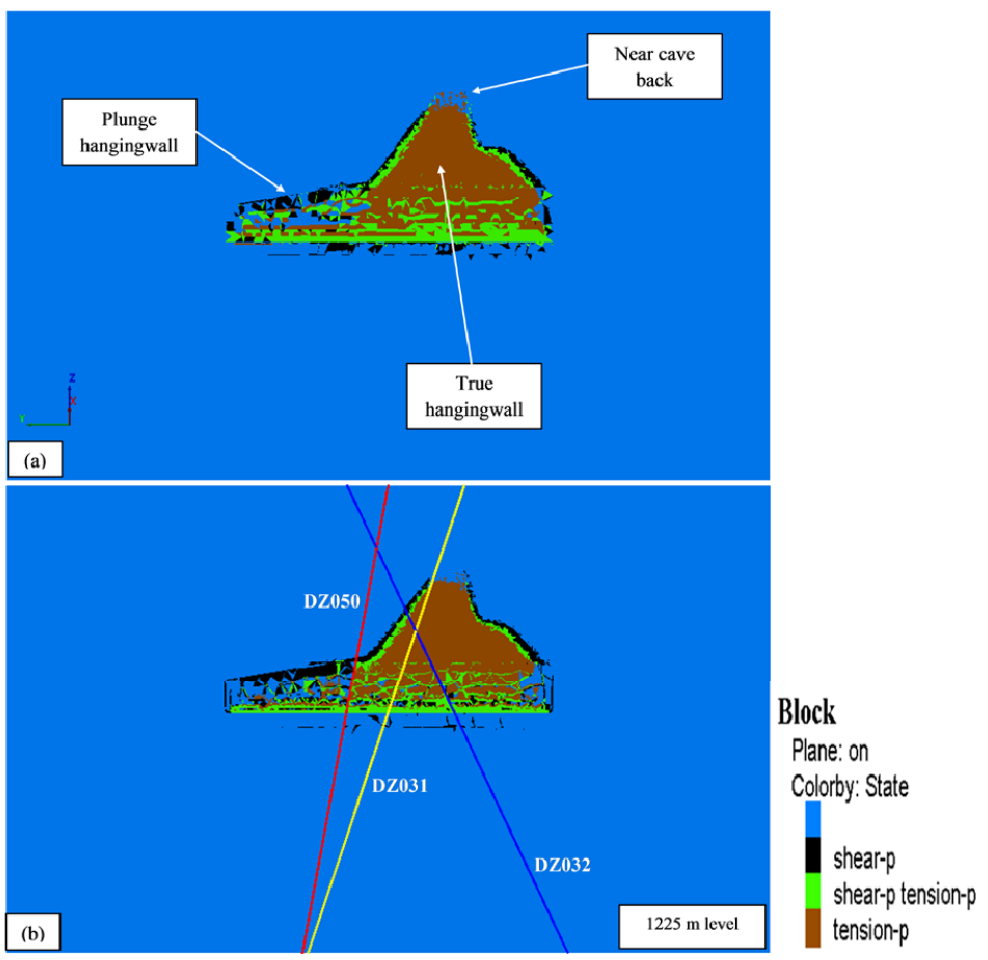

\section{Discussion}

Results from the discontinuum model showed that there was no effect from the largescale structures on the far-field stress redistribution in the Printzsköld orebody. Cohesion and friction angles were varied and their contribution to slip monitored. The large area of slip observed along structures DZ031 and DZ050 resulted from the near vertical dip and an orientation almost parallel to that of the maximum horizontal stresses. This setting gives a higher possibility for shear than when the structure is set at an oblique angle with respect to that of the maximum stress, similar to that for structure DZ032. A limitation with regard to the base case strength parameters was that they neglected the possible scale effects of the large-scale structures in a real sense. However, the laboratory-scale parameters were the best available parameters to use in the modelling. It is likely that the large-scale strength properties are lower than the ones measured in lab scale. Thus, the cases run with lower joint strength properties may be more realistic. Moreover, the results showed that if the large-scale parameters had a lower cohesion, this would not affect hangingwall or caprock stability as much as having a lower friction angle. It thus appears that the friction angle of large-scale structures has a more controlling effect on stability and cave initiation along the structures compared with the cohesion, at least for the strength variations simulated. Not all scenarios were tested, but suffice to say that 
increased slip would be expected if the cohesion was much lower. However, the consequence of using laboratory-scale properties, as has been shown, is that the amount of slip observed along the structures may be conservative.

As shown in Figure 10(b), all the three large-scale structures intersect the orebody at given points. As they slip, the slipping surfaces present points of failure genesis in the caving of the hangingwall. It can be considered that the structures have a potential to shape the cave geometry and affect cave propagation (in the event of caving through shear failure). This is likely to happen for the structures where slip is more pronounced such as DZ050 and DZ031. The presence of slip along the structures near the boundaries of the excavations at the intersections with the large-scale structures confirms a link found in studies by Vyazmensky et al. (2010) and Sainsbury et al. (2011b). In these studies, it was shown that geologic structures have an effect on the propagation and geometry of the cave formed as mining progresses. When the current cave boundary has failed, the process is likely to begin again as mining deepens and slip would be expected to be confined to the cave opening until it yields in shear. This process can continue as long as there is slip along the structures and as long as stress imbalances occur in the cap rock and hangingwall.

The continuum and discontinuum models highlighted that different results with added details can be obtained with the discontinuum modelling, whereas faster solutions could be obtained using the continuum modelling methodology. Woo et al. (2014) showed a similar result in their study for the testing of various numerical approaches for the influence on undercut depth on caving. The result from the comparison between the continuum and discontinuum model can be interpreted in the following ways:

- $\quad$ there is a loss of stress build-up in the evaluated areas (cap rock and cave bottom)

- the stress build-up lost has been due to the observed slip along the large-scale structures.

Moreover, the slip along the structures can provide an insight into the failure direction or caving advance especially since this slip is mostly confined to the cave boundaries.

\section{Conclusions and recommendations}

It has been found in this study that the large-scale structures simulated have no significant effect on the yielding of the hangingwall except for the slip which is confined to the cave boundary. Stress build-up was reduced in the discontinuum model, compared with the previous continuum models. This can be attributed to the shear slip that takes place along the structures. Moreover, plastic yielding of the rock mass has largely remained unaffected by the large-scale structures.

Lowering the strength parameters of the large-scale structures resulted in an increased area of slip along all the three structures. However, structure DZ032 showed fairly little increase in slip area. DZ031 and DZ050 had larger slip areas, because their strikes were nearly parallel with the direction of the maximum horizontal stress, thus resulting in higher shear stress and lower normal stress acting on these two structures. Thus, it is very important to consider the maximum stress direction in relation to the large-scale structures and the friction angle. 
This study has also shown that caving may be assisted by existing large-scale structures, attributed as slip developing near excavation boundaries. Consequently, the inferred large-scale structures in the Printzsköld orebody, and probably the entire mine, need further verification of their existence and locations. It is also recommended that future work should include studying the mining-induced seismicity in the cap rock and hangingwall. A mine-wide seismic network monitoring system has been in place at the Malmberget mine for several years and the collected data could be used to analyse patterns and identify linkages that may increase the understanding of both cave progression and how caving is affected by the structures.

The results of this modelling can be used as reference points for future caving analysis. Knowing the stress redistribution and effects of large-scale structures could give an insight into what to look for when caving operations are undertaken. It has been established from previous studies that the orientation of the structures influence the propagation and geometry of the cave formed. This study has looked at how varying the strength parameters will affect the cave initiation through slip along the structures. For future analysis, it hoped that the influence of both orientations and strength properties of the large-scale structures can be quantified.

\section{Acknowledgements}

This paper was written as part of an ongoing research project for Loussavaara Kirunavaara AB (LKAB) Malmberget Mine, Sweden. The project is funded through the Hjalmar Lundbohm Research Centre (HLRC). The support from LKAB and the Centre for Applied Mining and Metallurgy is acknowledged. The authors would also like to thank the following members of the research team for their various roles they played in making this research a smooth run: Jimmy Töyrä, Tomas Savilahti, Linda Jonsson, Joel Andersson and Fredrik Ersholm, all from LKAB. Also, thanks go to the Principal Supervisor of the first author, Adjunct Professor Jonny Sjöberg, as well as to Professor Erling Nordlund for their guidance and support during this research.

\section{References}

Banda, U.S. (2013) Rock Mass Characterization of the Printzsköld and Fabian Orebodies At the Malmberget Mine, Technical Report Luleå University of Technology, Luleå, ISBN 978-917439-822-9.

Brunton, I.D., Fraser, S.J., Hodgkinson, J.H. and Stewart, P.C. (2010) 'Parameters influencing full scale sublevel caving material recovery at the ridgeway gold mine', International Journal of Rock Mechanics and Mining Sciences, Vol. 47 pp.647-656.

Duplancic, P and Brady, B.H. (1999) 'Characterization of caving mechanisms by analysis of seismicity and rock stress', Proceedings of 9th International Congress on Rock Mechanics, Vol. 2, pp.1049-1053.

Herdocia, A. (1991) Hanging Wall Stability of Sublevel Caving Mines in Sweden, Doctoral Thesis, Luleå University of Technology, ISRN 1991:96/NR 1991:96, ISSN 0348-8373.

Itasca Consulting Group Inc. (2013) 3DEC (3-Dimensional Distinct Element Code), Version 5.0.

Lupo, J.F. (1997) 'Progressive failure of hanging wall and footwall Kiirunavaara Mine, Sweden', International Journal of Rock Mechanics and Mining Science, Vol. 34, Nos. 3-4, Paper No. 184. 
Lupo, J.F. (1998) 'Large-scale surface disturbance resulting from underground mass mining', International Journal of Rock Mechanics and Mining Sciences, Vol. 35, Nos. 4-5, p.399.

Magnor, B and Mattsson, H (2010) Strukturgeologisk Modell Över Malmbergets Gruvområde. Internal Rapport, Hifab, Geovista.

Martinsson, O and Hansson, K.E. (2004) 'Apatite iron ores in the Kiruna area: day seven field guide', in Allen, R., Martinsson, O. and Weihed, P. (Eds.): Svecofennian Ore-Forming Environments Field Trip Volcanic-Associated $\mathrm{Zn}-\mathrm{Cu}$-Au-Ag and Magnetite-Apatite, SedimentHosted Pb-Zn and Intrusion-Associated Cu-Au Deposits in Northern Sweden, Society of Economic Geologists Guidebook, Littleton, Colorado, pp.65-88.

Romer, R.L. (1996) 'U-Pb system of stilbite-bearing low-temperature mineral assemblages from the Malmberget iron ore, Northern Sweden', Geochim Cosmochim Acta, Vol. 60, pp.1951-1961.

Sainsbury, B. (2012) A Model for Caving Propagation and Subsidence Assessment in Jointed Rock Masses, Doctoral Thesis, The University of New South Wales, Australia.

Sainsbury, B., Pierce, M and Mas Ivars, D. (2008) 'Simulation of rock mass strength anisotropy and scale effects using a ubiquitous joint rock mass (UJRM) model', Proceedings First International FLAC/DEM Symposium on Numerical Modelling, Minneapolis, MN, USA, pp.25-27.

Sainsbury, B., Pierce, M and Mas Ivars, D. (2009) 'Analysis of caving behavior using a synthetic rock mass - ubiquitous joint rock mass modeling technique', Proceedings of the 1st Southern Hemisphere International Rock Mechanics Symposium (SHIRMS), Australian Centre for Geomechanics, Perth, pp.243-254.

Sainsbury, B.L. (2010) 'Sensitivities in the numerical assessment of cave propagation in caving', Second International Symposium on Block and Sublevel Caving, 20-22 April, Australian Centre for Geomechanics, Perth.

Sainsbury, B.L., Sainsbury, D.P and Pierce, M.E. (2011a) 'A historical review of the development of numerical cave propagation simulations', 2nd International FLAC/DEM Symposium in Numerical Modelling, 14-16 February, Itasca International Inc., Mineapolis.

Sainsbury, D.P., Sainsbury, B.L., Board, M.P. and Loring, D.M. (2011b) 'Numerical back-analysis of structurally controlled cave initiation and propagation at the Henderson mine', 45th US Rock Mechanics/Geomechanics Symposium, 26-29 June, San Francisco, CA, USA.

Sjöberg, J and Jacobsson, L. (2007) Bergmekaniska Analyser För Ny Huvudnivå i MUJ (M1250), LKAB Utredning.07-701, 2007-03-01 (in Swedish).

Sjöberg, J. (2008) 'Three-dimensional unit stress tensor modeling of complex orebody geometry', 42nd US Rock Mechanics Symposium (ARMA), 29 June-2 July, San Francisco, CA, USA.

Skiöld, T. (1988) 'Implications of new U-Pb Zircon chronology to early proterozoic crustal accretion in Northern Sweden', Precambrian Res., Vol. 38, pp.147-164.

Umar, S.B., Sjöberg, J. and Nordlund, E. (2013) 'Rock mass characterization and conceptual modeling of the printzsköld orebody of the malmberget mine, Sweden', Journal of Earth Sciences and Geotechnical Engineering, Vol. 3, pp.147-173, ISSN 1792-9660.

Umar, S.B., Sjöberg, J. and Savilahti, T. (2015) 'Modeling of caving and deformation mechanisms of the hangingwall of the Printzsköld orebody in the Malmberget mine', Accepted for Publication in: The South African Institute of Mining and Metallurgy (SAIMM), in Press.

Villegas, T., Nordlund, E. and Dahnér-Lindqvist, C. (2011) 'Hangingwall surface subsidence at the Kiirunavaara mine, Sweden', Engineering Geololgy, Vol. 121, Nos. 1-2, pp.18-27.

Vyazmensky, A., Elmo, D. and Stead, D. (2010) 'Role of rock mass fabric and faulting in the development of block caving induced surface subsidence', Rock Mechanics and Rock Engineering, Vol. 43, pp.533-556.

Wettainen, T. (2010) Analys Och Prognostisering Av Uppblockning i Printzsköld, Master's Thesis, Luleå University of Technology, Luelå, Sweden, ISBN 1402-1617. 
Woo, K., Eberhardt, E., Elmo, D. and Stead, D. (2013) 'Empirical investigation and characterization of surface subsidence related to block cave mining', International Journal of Rock Mechanics and Mining Sciences, 7, Vol. 61, pp.31-42.

Woo, K., Eberhardt, E., Elmo, D., Stead, D. and Kaiser, P.K., (2014) 'Benchmark testing of numerical approaches for modelling the influence of undercut depth on caving, fracture initiation and subsidence angles associated with block cave mining, Mining Technology, Vol. 123, No. 3, pp.128-139. 